\title{
Greece and Social Impacts under Economic Crisis: An Example to Avoid?
}

\author{
G. Aspridis
}

Assistant Professor, Department of Business Administration, T.E.I. of Thessaly,

Email : aspridis@teilar.gr

L. Sdrolias

Associate. Professor, Department of Business Administration, T.E.I. of Thessaly,

Email : Isdrolias@teilar.gr

\section{Vasiliadis}

PhD, Faculty of Business and Economics, T.E.I. of Chalkida; Center of Education for Adults, Greek Ministry of Education, Chalkida, Greece, Email: labvas@yahoo.gr

\section{Kyriakou}

Economist, BSc, MSc, MBA Finance, University of Liverpool,

Doi:10.5901/ajis.2014.v3n3p171

Email :dimk21@gmail.com

\begin{abstract}
The global economy is experiencing its worst crisis and this is due to the globalization of markets. The proposed study is an attempt to record the social impact of the global economic crisis we are experiencing. For this reason, this paper presents the social, psychological, employment and political consequences of the economic crisis in Greece. Also, it will be presented, the way in which citizens perceive the crisis, in order to ascertain whether the welfare state and the process of European integration are affected. Finally what is the model of the modern welfare state to be established in Greece? What should be the characteristics of this and what are the prospects and the impact on human resources of businesses? How the relations between social groups are formed? The findings are particularly important and any utilization would contribute significantly to the understanding of the effects of the economic crisis and their treatment.
\end{abstract}

Keywords: Financial crisis, welfare state, human resources, social impacts.

\section{Introduction}

"The crisis afflicting some years now our place was marked by a highly tragic dimension. The increase in suicides. Those that are least known, since experts believe that their number always is considerably higher".

Stated in an article of the Archbishop of Athens and all Greece Ieronimos (Kathimerini, 10/20/2013, 21). Unfortunately this is only one dimension of the social implications of the memoranda.

In May 2010 it was agreed and voted in the Greek parliament the first memorandum. The ignorance of the majority of citizens, led to underestimation of its effects on both the economy and society. The aim was for the next three years the country to overcome the crisis and to be put on a growth trajectory with economic data to return to the pre-crisis period, namely in 2009.

All these predictions failed miserably. Memoranda affected wages, reduced consumption and reduced the standard of living in the country with particularly violent way. The effects of the economic crisis and the implementation of the memoranda are many and different for employees, pensioners and the unemployed. And these effects the authors will try to study and record in this paper.

\section{Literature Review}

By memorandum usually it is referred to a short text message from a person or a department to another. Informally, we 
refer to a written agreement between different parties. Generally, it is a formal diplomatic document in which opinions and thoughts on a matter are exchanged between governments and / or international organizations (the law does not recognize it as a contract of international law) (http://www.merriam-webster.com/dictionary / memorandum).

As a society we understand all of the people who live in one place or in one historical period and has wide (humanity) or tight fit (groups of people in time and space) as a concept. In alternative definition as a society is reportedly an in constant time collaborative group whose members have developed organized patterns of relationships through continuous interaction (http://www.merriam-webster.com/dictionary/society).

As health, according to World Health Organisation, is defined as "a state of complete physical, mental and social well being and not merely the absence of disease or infirmity" (WHO, 1946).

Economic crisis is a phenomenon in which an economy is characterized by a sustained and significant decline in economic activity. That all aggregates, such as employment, national product, pricing, and other investments. The key indicator of economic activity are investments, which fluctuate leading to drift and influence other financial indicators (Koufaris, 2010).

Marx and Engels wrote the "Manifesto of the Communist Party" (1848) saying that "in the crises an epidemic breaks out that in each other previous season it will have seemed like absurdity, the epidemic of overproduction. The society is suddenly thrown back into flash mode barbarity. (...) The industry and commerce seem to be destroyed. And why? Because in society there is too much civilization, too much means of subsistence, too much industry, too much commerce (...) How does the bourgeoisie overcome crises? On the one hand by enforced destruction of masses of productive forces. On the other by conquering new markets and exploiting deeper old ones. How then? By paving the way for more extensive and more destructive crises, and by diminishing the means whereby crises are prevented"(as cited in Milios, 1992).

\section{The Financial Crises in Greece and their Impact on Society}

The global economic recession of 1929 affected international trade, income, tax revenues, prices and profits. The economy of cities around the world were affected, especially those who depended directly on industry. The construction sector stalled, agricultural and livestock operations declined and unemployment has reached heights.

The bankruptcy of 1893 resulted in the Greek society to become more conservative and many social conflicts to occur, such as the Evangelika (1901) (translation of the Gospels in modern Greek language), the Oresteiaka (translation of Aeschylus' trilogy in modern Greek language), the emigration, urbanization, the movement in Goudi, the change in the political system and others (National Geographic, 2010). The events that punctuated the end of this period was the demonstration of farmers in Kileler and the election of the prime minister Eleftherios Venizelos.

The crisis of 1932 had an impact on society with many social conflicts, strikes, peasant uprisings, student protests and resulted in the collapse of the regime of the republic (Kondylis, 2010, National Geographic, 2010, Provopoulos 2009, Joll 2006, Abulafia 2004).

\section{The social impacts of the current crisis in Greek society}

The economic crisis leads to job insecurity, unemployment, poverty and ultimately leading to social exclusion more and more teams which is a source for various mental disorders. During the second quarter of 2013 the number of employed amounted to $3,632,184$ people and the unemployed to $1,350,435$. The unemployment rate was $27.1 \%$, versus $27.4 \%$ in the previous quarter and $23.6 \%$ in the corresponding quarter of 2012 (EL.STAT, 2013).

Unemployment also is associated with an increase in daily alcohol consumption, increase in suicides, domestic violence, but also to reduce road fatalities by $1.4 \%$. Poverty is associated with the occurrence of diseases as people are forced to surviving in a degraded environment, fed poorly and work in dangerous and unhealthy environments (Liaropoulos, 2010).

Research at the University of Oxford (reprinted in Financial Times) linking unemployment to 25\% with both morbidity and mortality in populations affected economically and highlights that the economic crisis in 26 European countries between 1970 and 2007 associated with a significant increase in mental disorders and alcoholism (Xanthaki, $\mathrm{nd})$.

More specifically, the percentage of reported suicides from $26.5 \%$ in 2011 shot up to $43 \%$ compared to 2007 , which was the last year before the crisis. In 2007 there were 328 suicides (268 men and 60 women), in 2008373 suicides (268 men and 65 women), in 2009 recorded 391 suicides (333 men and 58 women), in 2010 recorded 377 suicides (336 men and 41 women) and in 2011 recorded 477 suicides (393 men and 84 women). In the period January - August 2013 
all the facts concerning the suicides was 231 people (195 men and 36 women), according to the Centre for Suicide Prevention (http://www.suicide-help.gr/index.php?page = about).

Severe remains the problem of a diminishing workforce. This is due to two main reasons. First the low birth rate. Births have fallen by $10 \%$ since 2007 compared with 2012. According to the Minister of Health "the problem of low fertility in the Greek population increased continuously over the past two decades and significantly deteriorated last year, driven by strong economic crisis facing the country" (reprinted from the newspaper Dimokratia). Only in 2012 was recorded a population decline by $5.5 \%$, while that in the EU increased by $2.2 \%$. More specifically, 44,200 left the country, there were 116,700 deaths and 100,400 births (compared to 107,200 in 2011) (http://epp.eurostat.ec.europa.eu Istatistics_explained/index.php/Population_statistics_at_regional_level/el).

Second reason is the migration of Greek and especially young people abroad. According to preliminary data (even informally) during the years 2009 to 2011, immigrants to countries mainly in Western and Northern Europe and America exceed approximately 120,000 people. These men (about 60\% -70\%), aged 30-40 years (and / or greater), graduates (by more than 60\%) from Greek and foreign universities, master's or doctorate holders, middle-class or bourgeois offspring families (http://www.iefimerida.gr/node/99958 \# ixzz2ijwJZPEi).

Many Greeks living abroad emphasize that observe "significant increase in the number of Greek students seeking abroad for graduate studies and an intense escapism established within Greek scientists" (according to Professor Pashalidis G. of the University of Boston, in "K", Kathimerini , 10/20/2013). And it makes sense if you believe the evidence of EL.STAT. pursuant to which the decline in industrial production continues and the overall manufacturing industrial production has fallen by $1.2 \%$ in the period January - September 2013 compared with the corresponding period of 2012 (Tsimitakis, 2013).

Initial effects are referred to mental health of workers. At the international conference "Crises and Disasters. Psychosocial Impacts" (2013), which was organized by the Greek Psychiatric Association and the World Federation for Mental Health, in collaboration with the Society for Preventive Psychiatry, emerged that the dismissal of workers leads to an increase in suicide rates and argued that the dismissal from work, beyond the economic impact also entails a humiliating blow to the employee resulting from the reduction of family and social status (http:/liatropedia .com/articles/read/3744).

A study by the University Research Institute of Mental Health, under the Academic Costas Stefanis for 2013 observed that depression has a significant increase of $57.6 \%$ for women and $42.9 \%$ men. Women in the age group 55 to 64 had the highest rate of depression (23\%) while the age group for males was 35-44 (16.4\%). Also, the third people suffering from depression has reduced costs for basic necessities, it has sold $7.4 \%$ of the movable and immovable property and $22.6 \%$ spent part or all of their savings (Ethnos of Sunday).

Due to the economic crisis, a new balance within the family has been formed. In a survey of People for Business society on "Crisis and family balances" (held from 15/10/2012 to 15/12/2012, a sample of 365 senior and middle management employees) showed that $49.1 \%$ of male executives, as still had their job, ensured fees constituted $50-80 \%$ of the family income, while $30.9 \%$ of strains before exiting unemployment had income that exceeded $80 \%$ of the family income. $20 \%$ of executives salary does not exceed $50 \%$ of total family income. During the same period the incomes of their spouses were much smaller than the total family income. Today the situation is completely different. The survey shows that $60 \%$ of women cover most, over $50 \%$ of the family income. Specifically, $45.5 \%$ of women provide more than $80 \%$ of family income, $16.4 \%$ cover $50-80 \%$ of the total income in home and $38.2 \%$ earning wages not exceeding $50 \%$ of family income. Turning now to the form of employment held by wives, $69.1 \%$ have a permanent job and $30.9 \%$ temporary. The percentage of women who have paid employment is $72.7 \%$, while women who work as freelancers touching only $27.3 \%$ (http://gr.euronews.com/2013/02/21/greece-crisis-research-ereuna-krisi-oikogeniakes-isorropies/).

$70 \%$ of pensioners receive pensions below $750 €$, while it is characteristic that Greece has the highest proportion of private health expenditure reached $57.1 \%$. Salaries, pensions and other social costs remain low, while labor rights are reduced because of the elasticity of working relationships and market. Beside the unemployed - poor, workers - poor re proliferated fast. At the same time, workers accept distribution patterns of poverty and unemployment that turn us back several years (website http://www.insurancedaily.gr/blog/?p=19475, accessed on the 17/8/2011).

A research by the Skilled Chamber of Thessaloniki (V.E.TH.) demonstrated that $40 \%$ of pensioners forced to work to survive, while $69 \%$ consider that the pension is low. Furthermore, $43 \%$ answered that worsened his life after retirement (Tsiantos, 2010).

In a Eurobarometer survey (May 2010), about the social impact of the crisis on countries - EU members, Greeks appear to occupy the first place among EU citizens to consider how badly they have been affected by the crisis. $69.3 \%$ of Greeks thought that the next twelve months will be worsening economic situation of their households. $43.9 \%$ of people stated that giving constantly struggle to pay household bills and $93.7 \%$ of our fellow citizens believe that poverty has risen 
in Greece last year. $28.8 \%$ of people stated that during the last twelve months there was time when he had no money to pay utility bills, buy food or other consumer goods. $30.2 \%$ of people expressed fears that the next twelve months were likely not be able to pay timely the rent of their home or a loan. $34.9 \%$ of Greeks employed stated that the next twelve months is not too sure how to maintain their current job and $73 \%$ believed that it is "unlikely or very unlikely" to find a job if they go redundant (http://www.megaline.gr/2010-02-27-18-58-37/255-0i-epiptoseis-oikonomikhs-krisis-2010.html, accessed on the 28/5/2011).

The World Health Organization (WHO) warned in January 2009 the effects of the global economic crisis. It emphasized that the first priority in every country will face steep economic decline, should be the protection of life and property of citizens who will be at greater risk. It observed increase in crime, especially in urban centers which undergo the greatest pressure from unemployment and job insecurity. One issue that takes explosive proportions, is the increase in suicides for economic reasons. At newspaper "Proto Thema" refers to "a Greek commits suicide every day due to debts" (Tsiantos, 2010). Also, WHO announced that the economic crisis threatens to undermine public health and the lack of action will lead to bigger problems in society, the economy and health (Konstantaras, 2013).

Crime rate is directly affected by the memoranda. Many people resort to crime in order to secure their livelihood. The result is the collapse of the system of values, morality and social control system is unable to control the whole situation. According to official figures, crime rates increased from $15 \%-20 \%$. This increase is mainly due to the increase of petty crime in relation to felonies (http://www.enet.gr/?i=news.el.article\&id=391423).

Even relevant indicators show a reduction of the welfare state in Greece. According to the Welfare Index of the British Legatum Institute in 2010, for the most prosperous country in the world, Greece is ranked 39th in the relevant list (first is Norway). The comparatively "strong" parts of Greece, according to the Welfare Index, are twofold. Education and health. "Moderate" with yellow mark on the index is the economy, entrepreneurship and opportunity, governance and security. In "red" are individual freedoms and social capital (the website http://www.tovima.gr/world/article/?aid=363555, accessed on the 19/8/2011). Page for Greece is http://www.prosperity.com/country.aspx?id=GR (accessed on the 19/8/2011).

For the year 2012 the situation in the country deteriorated. More specifically Greece is in 49th position among 142 countries. Education and health remain the most powerful parts of Greece, while the economy (85th place) and personal freedoms (121st place in the table) are the weakest parts of the country (http://www.prosperity.com/CountryProfile. aspx? $\mathrm{id}=300)$.

Last and most important impact is the effect on 3rd Greek Republic. Professor Kalyvas mentioned that "Rereading it these [the book of Juan Linz" Collapse of democratic regimes"(1978)] days I was impressed with the similarities with today's Greece: Weakness and inefficiency of the parties - the backbone of 3rd Republic, delegitimation of democratic institutions, rising edges, bloom to political violence : All the ingredients are here. We are moving, therefore, headlong towards collapse?" (Kalyvas, 2013).

And this of course because education is lacking. In a survey of Eurobarometer (2013), only 5\% of respondents reported "high" or "very high" participation in cultural activities. And the numbers are worse when it comes to reading. There, 50\% said they have not read a single book in the past 12 months (Chrysoloras, 2013).

Table 1 : The implications of the memoranda by social sector

\begin{tabular}{|l|ll|}
\hline \multicolumn{1}{|c|}{ Sector } & Impacts \\
\hline Democracy & - & \multicolumn{1}{c|}{ Collapse of current political system? } \\
\hline Criminality & - Increase of minor-criminality \\
\hline \multirow{3}{*}{ Health } & - & Reduction of the welfare state \\
& - & Mental health problems \\
& - Increase in suicides \\
& - Mortality of population \\
\hline \multirow{2}{*}{ Workforce } & - Morbidity of population \\
\hline Demographics & - Increase of unemployment \\
\hline Society & - Salary reduction \\
\hline
\end{tabular}

Source: Personal Data Utilisation 


\section{Epilogue}

Of all the previous reports, we assure that the economic crisis creates serious problems in all areas of the welfare state. This is due to many different reasons, such as the restrictions on the use of social services, the reduction of services and reducing of income. It is necessary to strengthen the welfare state and social cohesion.

Greeks are frustrated by the situation so far and do not distinguish immediate improvement of their economic policy and labor relations in the near future. They believe that the welfare state is constantly decreasing and cannot cope with the increasing problems posed by the economic crisis. And the result of all this is to show the same phenomena of social pathology as had occurred in the past, ie the society is being more conservative, immigration is increasing (according to a report in Kathimerini 2/9/2010, hundreds of thousands of individuals and companies have applied to go abroad - even worst wave than the one of the 1950s) (which is revealed in an interview with Professor Mark Mazower, 2011).

\section{References}

Abulafia, D., (2004), The Mediterranean in History, Athens : Patakis (in Greek).

Ethnos of Sunday (2013). «The crisis ejects psychiatric morbidity», 24/11/2013 (28-29) (in Greek).

European Commission, (2009). «Economic and Financial Affairs: Economic crisis in Europe : Causes, consequences and responses», European Economy, Brussels (1 - 87).

Eurostat, (2013). Eurostat regional yearbook 2013, Brussels : Eurostat.

Joll, J., (2006), Europe 1870 - 1970, Athens : Vanias (in Greek).

Hellenic Statistical Authority, (2013). Press Release - Labour Force Survey - second quarter 2013, Piraeus (in Greek).

Kalyvas, St., (2013). «Juan Linz and the collapse of democratic regimes», Kathimerini, 13-10-2013 (in Greek).

Kondylis, Th., (2010), 1929 - 1932 : The global economic crisis and the Greek bankruptcy, EuroCapital http://www.eurocapital.grlindex .php/permalink/13126.html (accessed on the 28/5/2011).

Koufaris, G., (2010). «Global financial crisis and stock market», Chrima, January - February 2010.

Krugman, P., (2009). The crisis of 2008- And the return of economic recession, Athens : Kastaniotis (in Greek).

Konstantaras, N., (2013). «Alarm about the health of Europe», Kathimerini, 3/11/2013 (20) (in Greek).

Liaropoulos, (2010). Organization of health services and systems, Athens : Beta Medical Editions.

Mazower, M., (2011), «The crisis in Greece began in 1990», interview to M. Pournara, Kathimerini, 17/7/2011, p. 10 (in Greek).

Milios, G., (1992). «The Marxist historical discussion of economic crises (1900-1935)», Theseis, v. 41, October - December 1992 (in Greek).

National Geographic, (2010), Major Reconstruction 1900 - 1930 - 1950 The recovery of Greece after the economic storms of the 20th century, Athens.

Xanthaki, Art., (nd), Psychological effects of the economic recession, on the webpage http://www.dietup.gr/antras/psyxikh-ygeia/3183psyxologikes-epiptwseis-ths-oikonomikhs-yfeshs.html (accessed on the 28n/5/2011) (in Greek).

Provopoulos, G., (2009), The two global crises (1929 and today) and the Greek economy: Some critical - and useful - comparisons, Workshop by the Parliament Foundation for Parliamentary System and Democracy, Athens, on the webpage http://www.bankofgreece.gr/Pages/el/Bank/News/Speeches/Displtem.aspx?Item_ID=103\&List_ID=b2e9402e-db05-4166-9f09e1b26a1c6f1b (accessed on the 8n/6/2011).

Ravitch, D., (2010). The death and life of the great American school system, NY : Basic Books.

Tsiantos, B., (2010), Social impacts of the economic crisis, on the webpage, http://www.k-tipos.gr/ktipos/detail.php?ID=810 (accessed on the $28 n / 5 / 2011)$.

Tsimitakis, M., (2013). «Something happens to industrial production in Greece», Kathimerini, 8/12/2013 (in Greek).

World Health Organization, (1946). International Health Conference, WHO : New York.

Chrysoloras, N., (2013). «The Greek of «@diversity»»), Kathimerini, 5/11/2013 (in Greek).

\section{Websites}

http://gr.euronews.com/2013/02/21/greece-crisis-research-ereuna-krisi-oikogeniakes-isorropies/, accessed on the 22/10/2013.

http://www.megaline.gr/2010-02-27-18-58-37/255-oi-epiptoseis-oikonomikhs-krisis-2010.html, accessed on the 22/10/2013.

http://www.tovima.gr/world/article/?aid=363555, accessed on the 22/10/2013.

http://www.prosperity.com/country.aspx?id=GR, accessed on the 22/10/2013.

http://www.insurancedaily.gr/blog/?p=19475, accessed on the 22/10/2013.

http://iatropedia.com/articles/read/3744, accessed on the 22/10/2013.

http://gr.euronews.com/2013/02/21/greece-crisis-research-ereuna-krisi-oikogeniakes-isorropies/, accessed on the 22/10/2013.

http://www.merriam-webster.com/dictionary/memorandum, accessed on the 24/10/2013.

http://www.merriam-webster.com/dictionary/society, accessed on the 24/10/2013. 
http://www.suicide-help.gr/index.php?page=about, accessed on the 24/10/2013.

http://www.prosperity.com/CountryProfile.aspx?id=300, accessed on the 24/10/2013.

http://www.enet.gr/?i=news.el.article\&id=391423, accessed on the 24/10/2013.

http://www.dimokratianews.gr/content/18857/\%CE\%BC\%CE\%B5\%CE\%AF\%CF\%89\%CF\%83\%CE\%B7-10-

\%CF\%84\%CF\%89\%CE\%BD-\%CE\%B3\%CE\%B5\%CE\%BD\%CE\%BD\%CE\%AE\%CF\%83\%CE\%B5\%CF\%89\%CE\%BD-

$\%$ CE\%BB\%CF\%8C\%CE\%B3\%CF\%89-

\%CE\%BC\%CE\%BD\%CE\%B7\%CE\%BC\%CE\%BF\%CE\%BD\%CE\%AF\%CE\%BF\%CF\%85, accessed on the 25/10/2013.

http://www.iefimerida.gr/node/99958\#ixzz2ijwJZPEi, accessed on the 25/10/2013.

http://epp.eurostat.ec.europa.eu/statistics_explained/index.php/Population_statistics_at_regional_level/el, accessed on the 25/11/2013. 